УДК 597-19

\author{
В. Г. Терещенко
}

Институт биологии внутренних вод им. И. Д. Папанина РАН

\title{
РАВНОВЕСНОЕ СОСТОЯНИЕ СООБЩЕСТВА ГИДРОБИОНТОВ
}

Проанализирована многолетняя динамика разнообразия рыбного населения около 70 крупных озер и водохранилищ России и стран СНГ. Предложен метод поиска равновесного состояния водных сообществ. Установлено, что индекс доминирования рыбного населения в стабильном состоянии чаще равен 0,3. Выявлены факторы, определяющие разнообразие рыбного населения озер и водохранилищ.

\section{В. Г. Терещенко}

Інститут біології внутрішніх вод ім. І. Д. Папаніна РАН

\section{СТАН РІВНОВАГИ В УГРУПОВАННЯХ ГІДРОБІОНТІВ}

Проаналізовано багаторічну динаміку різноманіття рибного населення близько 70 великих озер і водосховищ Росії та країн СНД. Запропоновано метод відшукування стану рівноваги водних угруповань. Установлено, що індекс домінування рибного населення у стабільному стані найчастіше дорівнює 0,3. Виявлено фактори, які визначають різноманіття рибного населення озер і водосховищ.

$$
\text { V. G. Tereshchenko }
$$

Institute for Biology of Inland Waters Russian Academy of Sciences

\section{THE STABLE STATE OF AQUATIC ASSEMBLAGE}

Long-term dynamics of fish assemblage diversity of more than 70 lakes and reservoirs of Russia and the CIS countries were analyzed. The method of revealing of stable state of aquatic assemblages is offered. It is established, that most often the index of domination of the stable fish assemblage is equal 0.3 . The factors determining a diversity of the fish assemblage of lakes and reservoirs are revealed.

\section{Введение}

Концепция «устойчивое развитие» биологических ресурсов стала в настоящее время одной из основных при их эксплуатации, что обусловлено как необходимостью бережного и рационального отношения к ним, так и научным обеспечением выполнения международных обязательств странами, подписавшими Конвенцию по биоразнообразию [20]. Однако достаточно рассмотреть многолетнюю динамику добычи любого биологического ресурса, чтобы понять, насколько практика далека от решения поставленной задачи. Вместе с тем, трудами многих ихтиологов России и стран СНГ накоплен уникальный обширный материал, который позволяет на примере рыб подойти к исследованию условий, при которых сообщество гидробионтов находится в равновесном состоянии, какие воздействия выводят его из этого состояния и как быстро оно приходит в норму, какие вообще характерны стационарные состояния. Цель данной работы - определение понятия равновесного состояния рыбного населения, описание метода его выявления и основных выявленных закономерностей.

(C) В. Г. Терещенко, 2009 


\section{Материал и методы исследований}

Работа основана на данных по многолетней динамике структуры уловов рыб более 70 крупных промысловых водоемов СНГ, на которых был хорошо налажен промысел, а в большинстве водоемов вылавливалось и учитывалось до половины обитающих в них видов [7-9; 11-13; 18]. Взят суммарный вылов за год, что нивелирует колебания видового состава уловов, так как они получены в разные сезоны, в различных биотопах и с применением разных орудий лова [15]. Поскольку доля «мелочи III группы» в большинстве случаев невелика, информация по этой группе в расчетах не учитывалась. Оценка вклада малочисленных (и не учитываемых статистикой) видов рыб показала, что потеря этой информации приводит к относительной погрешности индекса разнообразия не более 15 \% [17]. Взяты лишь данные рыбопромысловой статистики с начала формирования водохранилищ, а озер - с начала 1940-х до конца 1980-х годов, то есть в годы, когда информация по структуре уловов рыб была репрезентативной [10].

Под равновесным состоянием рыбного населения мы понимаем состояние, при котором уровень воспроизводства основных популяций рыб, обитающих в данном водоеме, находится в относительном динамическом равновесии с величиной их смертности. В этом состоянии минимальна вариабельность урожайности поколений большинства видов рыб, стабильны интегральные структурные показатели (разнообразие и доминирование) и относительное обилие видов, относящихся к разным экологическим группам. Равновесное состояние можно рассматривать и как состояние, в которое рыбное население приходит после прекращения действия нарушающего воздействия, то есть его можно рассматривать как зону притяжения системы или аттрактор.

Метод определения равновесного состояния состоит в анализе многолетней динамики структурных или функциональных характеристик и выявлении периодов их минимальной вариабельности. Поскольку структура сообщества тесно связана с его функционированием [2], для выявления равновесных состояний анализировали структурные показатели. Интегральное описание видовой структуры рыбного населения, отражающее как изменение числа видов, так и перераспределение их относительного обилия, основано на индексе разнообразия по Шеннону [4; 6]:

$$
\mathrm{H}=-\sum_{\mathrm{i}=1}^{\mathrm{K}}\left(\mathrm{n}_{\mathrm{i}} / \mathrm{N}\right) \times \log _{2}\left(\mathrm{n}_{\mathrm{i}} / \mathrm{N}\right),
$$

где $n_{i}$ - обилие $i$-й группы, $N$ - суммарное обилие всех групп, $K$ - число видов.

Дополнительно анализировали индекс доминирования $R$, называемый «относительная организация», зависящий только от вклада различных видов [3]:

$$
\mathrm{R}=1-\mathrm{H} / \log _{2} \mathrm{~K} .
$$

Различные воздействия приводят к перестройкам в структуре сообщества. Важно, что они проходят за определенное время путем последовательных преобразований. Следовательно, реакция сообщества на внешние воздействия в значительной мере обусловлена его инерционностью [14], а само сообщество относится к сложным динамическим системам [3]. Один из эффективных методов анализа динамической системы состоит в получении ее «динамического фазового портрета» [5]. Он дает возможность выявить стационарные состояния системы и характер ее динамики при отклонении от них. Использование этого метода для анализа структурных изменений в реальных сообществах гидробионтов нами подробно описано ранее [16].

Суть метода динамического фазового портрета состоит в исследовании поведения системы в пространстве ее состояний, то есть в координатах $(d H / d t, H)$, где $d H / d t-$ 
скорость изменения индекса разнообразия, $H$ - разнообразие рыбного населения, $t-$ время. Анализ основан на поиске стационарных или равновесных точек, то есть зон, в которых скорость изменения разнообразия близка к нулю. Индикаторы реакции на возмущающее воздействие - переход системы в другое состояние или нарушение плавности кривой фазового портрета. Из теории известно, что у самой простой нелинейной системы стационарные состояния - это точки пересечения параболы с осью нулевой скорости изменения разнообразия [1]. При удалении от равновесной точки фазовый портрет имеет вид выпуклой или вогнутой дуги. Для колебательной системы в зависимости от знака и соотношения коэффициентов уравнения, которым она описывается, стационарные состояния будут называться: центр, устойчивый и неустойчивый фокус, устойчивый и неустойчивый узел, седло [5; 14]. Для первых трех стационарных состояний фазовый портрет имеет вид циклических траекторий, закручивающейся и раскручивающейся спиралей.

\section{Результаты и их обсуждение}

Анализ имеющегося у нас материала показал, что устойчивое состояние рыбного населения наблюдается в следующих случаях.

1. Рыбное население стабильно. В этот период наблюдается минимальная амплитуда колебаний индекса разнообразия. Траектория системы на фазовом портрете имеет вид или закручивающейся спирали (особая точка - «устойчивый фокус»), или эллиптической кривой (особая точка - «центр»), или раскручивающейся спирали (особая точка - «неустойчивый фокус»). При этом скорость структурных перестроек не превышает 0,1 бит/год.

2. Рыбное население находится в стадии формирования или после нарушающего воздействия отклонилось от равновесного состояния и стремится к нему. При этом скорость структурных перестроек может доходить до 0,4 бит/год. Траектория системы на фазовом портрете имеет вид выпуклой или вогнутой дуги. Путь выявления состояния равновесия - рассмотрение фазового портрета в периоды нахождения рыбного населения далеко от состояния равновесия и отыскания точки пересечения параболы и оси $d H / d t=0$.

3. Рыбное население находится в стадии формирования и во время приближения системы к равновесному состоянию на водоем оказано сильное нарушающее воздействие, которое привело к изменению равновесного состояния. Тогда фазовый портрет принимает вид соединенных вместе двух выпуклых или вогнутых дуг. Этот случай выявления равновесного состояния основан на положении о том, что оно может быть рассмотрено как точка притяжения сообщества или аттрактор.

В структуре уловов рыб более 70 крупных промысловых озер и водохранилищ России и стран СНГ за 30-летний период их существования отмечены равновесные состояния, разнообразие которых находилось в пределах 0,6-3,2 бит (рис.). Наиболее часто встречались равновесные состояния с разнообразием уловов 1,7-1,8 бит и 2,52,8 бит. При этом отсутствуют достоверные отличия в средних значениях индекса разнообразия для выборки отдельно по озерам и водохранилищам. Доминирование структуры рыбного населения, находящегося в равновесном состоянии, лежало в диапазоне 0,1-0,7 при наибольшей частоте встречаемости значения 0,3. Интересно отметить, что у зоопланктона, находящегося в устойчивом состоянии, наблюдались сходные значения индексов доминирования (устное сообщение В. Б. Вербицкого).

Рыбное население относится к сложным самоорганизующимся системам. В связи с этим его структура не случайна, а определяется межвидовыми связями и действи- 
ем среды. Она определяется неоднородностью местообитания, площадью, стабильностью среды, продуктивностью, наличием хищников и т. д. [4; 6].
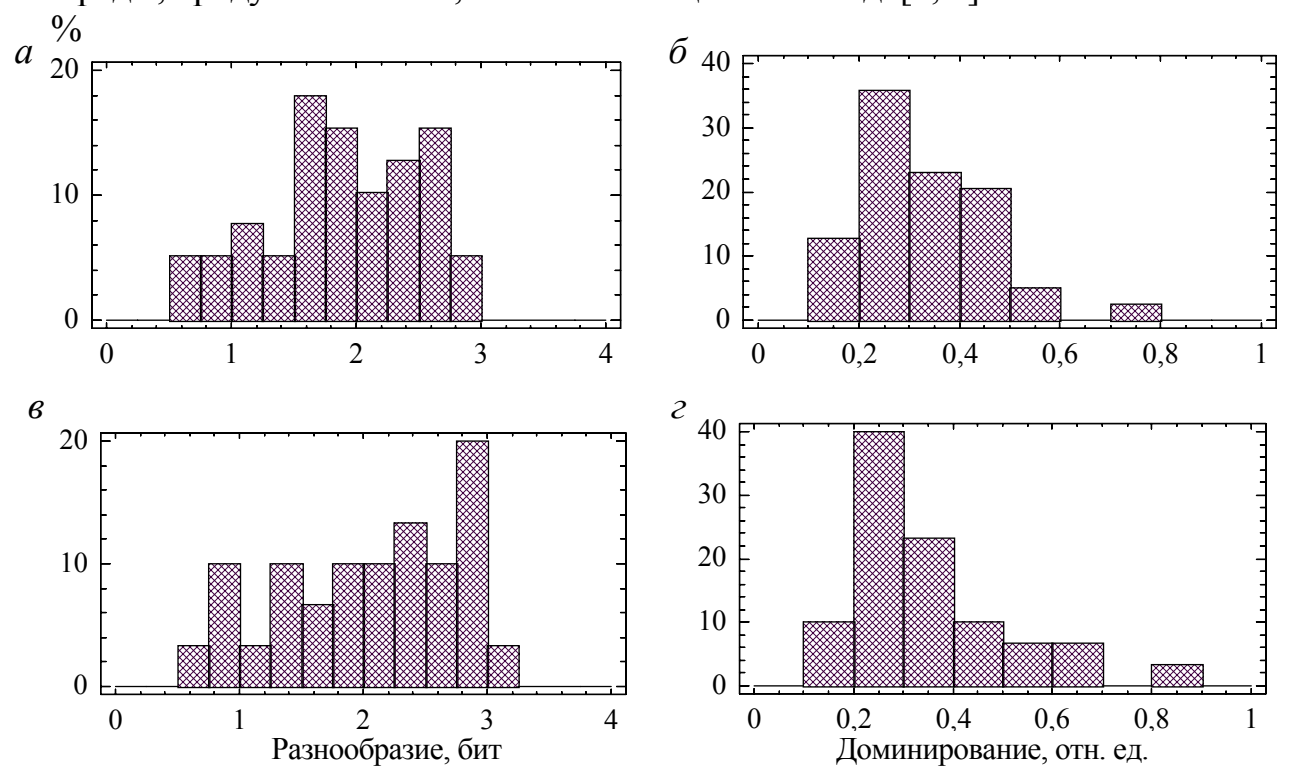

Рис. Стационарные (равновесные) уровни разнообразия $(a, \boldsymbol{c})$

и доминирования $(\sigma, 2)$ рыбного населения соответственно озер и водохранилищ

Для изучения функциональных основ организации рыбной части сообщества проанализирована связь равновесных уровней разнообразия рыбного населения озер и водохранилищ со свойствами водоема (географической широты, площади и глубины), составом ихтиофауны (видовом богатством, долей хищников) и промысловой рыбопродуктивностью. При уровне значимости $p=0,05$ установлена достоверная связь (корреляция по Спирмену) разнообразия рыбного населения озер и водохранилищ, находящихся в равновесном состоянии, с видовым богатством ихтиофауны, долей хищников в улове, рыбопродуктивностью, скоростью водообмена и географической широтой, то есть климатическими факторами. Однако для разных групп водоемов (озера и водохранилища, озера с насыщенной и ненасыщенной ихтиофауной) число и значимость отдельных факторов различны (табл.).

Таблицча

Связь разнообразия рыбного населения со свойствами водоема и составом ихтиофауны: показатели корреляции по Спирмену при $\boldsymbol{p}=\mathbf{0 , 0 5}$

\begin{tabular}{|l|c|c|c|c|c|c|c|}
\hline \multicolumn{1}{|c|}{ Водоемы } & $\begin{array}{c}\text { Географическая } \\
\text { широта }\end{array}$ & \% хищников & Число видов & Улов/га & Площадь & Глубина & $\begin{array}{c}\text { Водо- } \\
\text { обмен }\end{array}$ \\
\hline Модельные водоемы & 0,52 & 0,40 & 0,35 & - & - & - & - \\
\hline Все водоемы & 0,32 & 0,41 & 0,35 & - & - & - & - \\
\hline Водохранилища & - & - & 0,63 & 0,30 & - & - & 0,54 \\
\hline Все озера & 0,58 & 0,36 & 0,38 & - & - & - & - \\
\hline $\begin{array}{l}\text { Озера с насыщенной } \\
\text { ихтиофауной }\end{array}$ & 0,48 & - & - & - & - & - & - \\
\hline $\begin{array}{l}\text { Озера с ненасыщен- } \\
\text { ной ихтиофауной }\end{array}$ & 0,70 & 0,40 & 0,40 & - & $-0,40$ & - & - \\
\hline
\end{tabular}

Для хорошо изученных (модельных) водоемов ведущими факторами, определяющими разнообразие рыбного населения, оказались климатические (географическая 
широта), влияние хищников и видовое богатство ихтиофауны. А для более молодых экосистем (водохранилищ) важными в формировании разнообразия рыбного населения оказались следующие факторы: видовое богатство, продуктивность и величина водообмена.

\section{Заключение}

Анализ приведенных данных позволил утвердительно ответить на вопрос о существовании равновесных состояний рыбного населения. Отмечены равновесные состояния, при которых разнообразие находилось в пределах 0,6-3,2 бит при модальном значении доминирования 0,3. Факторами, влияющими на формирование разнообразия рыбного населения озер и водохранилищ России и стран СНГ, можно считать видовое богатство ихтиофауны, обилие хищников, рыбопродуктивность, скорость водообмена и климатические факторы. Однако для разных групп водоемов значимость каждого из факторов различна.

Проведенный анализ структурных перестроек в рыбном населении показал, что модифицированный метод динамического фазового портрета может быть применен к анализу реальных сообществ. Он позволил более полно использовать информацию, заключенную в статистике уловов, выявить равновесную структуру рыбной части сообщества и наглядно представить характер ее динамики при нахождении в равновесии и под прессом нарушающих воздействий.

Разрабатываемый нами метод базируется на выявлении равновесных уровней разнообразия, то есть зоны устойчивого функционирования сообщества или его части, и степени отклонения от этой зоны. При этом поведение рыбного населения в названных характерных зонах, описанное в терминах и формулах метода фазовых портретов, хорошо согласуется с известными общими закономерностями поведения биологических систем. Известно, что при отсутствии значимых воздействий наличие отрицательных обратных связей приводит к стабилизации системы, а выход ее из равновесного состояния свидетельствует об усилении степени воздействия [19].

Работа выполнена при поддержке гранта ОБН РАН по программе «Биологические ресурсы России».

\section{Библиографические ссылки}

1. Айламазян А. К. Информатика и теория развития / А. К. Айламазян, Е. В. Стась. - М. : Наука, 1989. $-174 \mathrm{c.}$.

2. Алимов А. Ф. Элементы теории функционирования водных экосистем. - СПб. : Наука, 2001. $-147 \mathrm{c}$.

3. Антомонов Ю. Г. Моделирование биологических систем. - К. : Наук. думка, 1977. - 248 с.

4. Бигон М. Экология. Особи, популяции и сообщества / М. Бигон, Д. Харпер, К. Таунсенд. В 2 т. - М. : Мир, 1989. - Т. 2. - 477 c.

5. Волькенштейн М. В. Общая биофизика. - М. : Наука, 1978. - 592 с.

6. Джиллер П. Структура сообществ и экологическая ниша. - М. : Мир, 1988. - 188 с.

7. Исаев А. И. Рыбное хозяйство водохранилищ / А. И. Исаев, Е. И. Карпова. - М. : Пищевая пром-сть, 1980. - 304 с.

8. Исаев А. И. Рыбное хозяйство водохранилищ / А. И. Исаев, Е. И. Карпова. - М. : Агропромиздат, 1989. $-255 \mathrm{c}$.

9. Ковалева М. П. Уловы и рыбопродуктивность водохранилищ СССР // Рыбохозяйственное изучение внутренних водоемов. - Вып. 11. - Л. : ГосНИОРХ, 1972. - С. 38-68.

10. Кудерский Л. А. Динамика рыбного населения озера / Л. А. Кудерский, А. С. Печников // Ладожское озеро: прошлое, настоящее, будущее. - СПб. : Наука, 2002. - С. 224-237. 
11. Лузанская Д. И. Рыбохозяйственное использование внутренних водоемов СССР. - М. : Пищевая пром-сть, 1965. - 600 с.

12. Лузанская Д. И. Промышленное рыболовство в озерах, реках и водохранилищах СССР // Вопросы экономики государственного и колхозного рыболовства. - Л. : ГосНИОРХ, 1970. C. 3-137.

13. Лузанская Д. И. Рыбохозяйственный водный фонд и уловы рыбы во внутренних водоемах СССР (справочник) / Д. И. Лузанская, Н. О. Савина. - М.-Л. : ВНИОРХ, 1956. - 514 с.

14. Романовский Ю. М. Математическое моделирование в биофизике / Ю. М. Романовский, Н. В. Степанова, Д. С. Чернавский. - М. : Наука, 1975. - 344 с.

15. Терещенко Л. И. О точности информационных характеристик видовой структуры ихтиоценоза / Л. И. Терещенко, В. Г. Терещенко // Вопр. ихтиологии. - 1987. - Т. 27, вып. 6. C. 919-923.

16. Терещенко В. Г. Метод фазовых портретов для анализа динамики структуры сообществ гидробионтов / В. Г. Терещенко, В. Б. Вербицкий // Биология внутр. вод. - 1997. - № 1. - С. 23-31.

17. Терещенко В. Г. Динамика разнообразия рыбного населения озер и водохранилищ России и сопредельных стран. Автореф. дис. ... д-ра биол. наук. - СПб, 2005. - 49 с.

18. Рыбохозяйственное освоение внутренних водоемов СССР в 1971-1975 гг. / Л. Н. Шимановская, Р. Я. Чистобаева, Л. Н. Танасийчук, Г. А. Новикова // Состояние рыбного хозяйства внутренних водоемов и методы прогнозирования рыбных запасов. - Л. : ГосНИОРХ, 1977. - С. 3-62.

19. Шмальгаузен И. И. Интеграция биологических систем и их саморегуляция // Кибернетические вопросы биологии. - Новосибирск : Наука, 1968. - С. 157-183.

20. Convention on Biological Diversity // Biology International. - 1992. - Vol. 25. - P. 22-39.

Надійшла до редколегії 12.10.2009 